\title{
PREVENTION EFFECTS OF METHANOLIC EXTRACT OF Eurycoma longifolia ROOTS ON CARBON TETRACHLORIDE-INDUCED HEPATOTOXICY IN RATS
}

\author{
Phebe Hendra $^{1 *)}$, Eustachia Diajeng Wandansari ${ }^{1}$, Elni Meilianti ${ }^{1}$, Bella Anggelina ${ }^{1}$, \\ Damiana Sapta Candrasari ${ }^{2}$, Fenty ${ }^{1}$
}

\author{
${ }^{1}$ Department of Pharmacology and Toxicology, Faculty of Pharmacy, Universitas Sanata Dharma, \\ Campus 3 Paingan, Maguwoharjo, Depok, Sleman, Yogyakarta 55282, Indonesia \\ ${ }^{2}$ Department of Pharmacognosy, Faculty of Pharmacy, Universitas Sanata Dharma, Campus 3 \\ Paingan, Maguwoharjo, Depok, Sleman, Yogyakarta 55282, Indonesia
}

Received June 7, 2018; Accepted October 2, 2018

\begin{abstract}
The objective of this study was to investigate preventive effects of methanolic extract of Eurycoma longifolia roots (MEEL) against carbon tetrachloride-induced hepatotoxicity in rats. A total of 25 rats were randomly divided into five groups $(n=5)$. Group I was treated with Sodium CMC $1 \% \mathrm{w} / \mathrm{v}$ (peroral, 6 days), and group II was treated with single dose of $\mathrm{CCl}_{4}$ in olive oil (1:1) $2 \mathrm{~mL} / \mathrm{kg}$ (intraperitoneal injection). Groups III-V received 75, 150, and $300 \mathrm{mg} / \mathrm{kg} \mathrm{BW}$ of MEEL (peroral, 6 days), respectively, and administration of $\mathrm{CCl}_{4}$ in olive oil (1:1) $2 \mathrm{~mL} / \mathrm{kg}$ (intraperitoneal injection) on the seventh day. The hepatoprotective potential was estimated by measuring serum activity of biochemical parameters. Further, liver weight ratio and histopathological changes were determined. The serum alanine aminotransferase (ALT), aspartate aminotransferase (AST), and lactate dehydrogenase (LDH) were significantly $(p<0.05)$ increased and albumin decreased significantly $(p<0.05)$ in the $\mathrm{CCl}_{4}$ treated group, but treatment with MEEL $75 \mathrm{mg} / \mathrm{kg}$ significantly $(p<0.05)$ prevented the elevation of ALT, AST, and LDH. Histopathological changes also indicated hepatic protection of the MEEL at $75 \mathrm{mg} / \mathrm{kg}$. This finding suggested that methanolic extract of Eurycoma longifolia roots at $75 \mathrm{mg} / \mathrm{kg}$ was enough to give a protective effect against $\mathrm{CCl}_{4}$-induced hepatotoxicity.
\end{abstract}

Keywords: carbon tetrachloride; Eurycoma longifolia; hepatotoxicity; protective

\section{INTRODUCTION}

The liver is a highly complex organ with regards to various physiological functions in the body (Joshi et al., 2015). An endogenous antioxidant system has been developed to maintain redox homeostasis in the liver. Homeostasis will be disturbed because of the excess of free radicals, resulting in oxidative stress, which plays a critical role in liver diseases and other degenerative disorders ( $\mathrm{Li}$ et al., 2015).

Non-alcoholic fatty liver disease (NAFLD) is defined by the presence of liver fat accumulation exceeding $5 \%$ of hepatocytes, in the absence of alcohol intake and any other cause of liver injury (Musso et al., 2011). NAFLD comprises a wide spectrum of liver damage, ranging from benign hepatocellular steatosis to non-alcoholic steatohepatitis, fibrosis, and cirrhosis (ElKader and Ashmawy, 2015). Prevalence of NAFLD in Asia is around 25\%, like many Western countries (Fan et al., 2017). Currently, NAFLD has become a worldwide problem and is associated with significant morbidity and mortality.

Carbon tetrachloride

$\left(\mathrm{CCl}_{4}\right)$ administration to rodents is a widely used model for hepatotoxicity study (Riordan and Nadeau, 2014). $\mathrm{CCl}_{4}$ is activated by 
cytochrome P450 2E1 to form trichloromethyl radicals $\left(\mathrm{CCl}_{3} \cdot\right)$ and trichloromethyl peroxyl radicals $\left(\mathrm{CCl}_{3} \mathrm{OO} \cdot\right)$. Free radical chain reactions lead to lipid peroxidation and finally produce reversible liver damage (Jayesh et al., 2017; Weber et al., 2003).

Medicinal plants contain a variety of secondary metabolites that can act as antioxidants. Antioxidants are vital substances which can protect the body from damage caused by oxidative stress induced by free radicals (Jothy et al., 2011). Eurycoma longifolia, which belongs to the Simaroubaceae family, is one of the most well-known herbal medicines in Southeast Asia (Khanijo and Jirangkoorskul, 2016; Rehman et al., 2016). The root possesses strong antioxidant properties (Varghese et al., 2013). Previous research has reported antihypertriglyceridemia, anti-inflammatory, analgesic, and anti-obesity activities in its methanolic extract (Hendra et al., 2017; Lahrita et al., 2017). Therefore, we aimed to investigate preventive the effects of Eurycoma longifolia roots extract against carbon tetrachloride-induced hepatotoxicity in rats.

\section{METHODS}

\section{Plant material and chemicals}

Eurycoma longifolia roots were collected from Kalimantan, Indonesia and supplied by Merapi Farma Herbal Co. (Yogyakarta, Indonesia). Plant material was identified and authenticated at the Department of Pharmaceutical Biology, Faculty of Pharmacy, Gadjah Mada University, Yogyakarta, Indonesia. A voucher specimen was deposited in the Laboratory of Pharmaceutical Biology, Faculty of Pharmacy, Sanata Dharma University, Yogyakarta, Indonesia. Sodium carboxymethyl cellulose (Sodium CMC) was supplied by Brataco Chemika, Indonesia. Olive oil was supplied from Bertolli, Italy. Methanol and carbon tetrachloride as hepatotoxins were from E. Merck (Darmstadt, Germany). Diagnostic kits for the estimation serum alanine aminotransferase (ALT), aspartate aminotransferase (AST), and albumin were purchased from Abbott Laboratories, Illinois, USA. Diagnostic kit for estimation of lactate dehydrogenase (LDH) in the serum was purchased from Thermo Fisher Scientific, Massachusetts, USA. All other chemicals were of analytical grade and were purchased from E. Merck, Darmstadt, Germany.

\section{Preparation of plant extract}

The dry powder of Eurycoma longifolia roots $(1.2 \mathrm{~kg})$ was extracted with methanol $(95 \% \mathrm{v} / \mathrm{v})$ in a mechanical shaker for $48 \mathrm{~h}$ at room temperature. The mixture was filtered, then concentrated by using a rotary evaporator at $60^{\circ} \mathrm{C}$ to yield a semi solid residue $(1.89 \%$ $\mathrm{w} / \mathrm{w})$. This methanolic extract of Eurycoma longifolia roots (MEEL) was kept in a desiccator and used for further experiments.

\section{Phytochemical screening}

The MEEL was screened for various chemical constituents (flavonoids, alkaloids, tannins, phenolic compound, alkaloids and terpenoids) by using established methods (Harborne, 1973; Evans and Trease, 1989).

\section{Experimental animals}

Adult male Wistar rats weighing 150-250 $\mathrm{g}$ were used for this experiment. The animals were procured from Department of Pharmacology and Therapy, Faculty of Medicine, Gadjah Mada University, Yogyakarta, Indonesia. Five rats were kept in one cage and acclimatized to the surroundings (Pharmacology and Toxicology Laboratory, Faculty of Pharmacy, Sanata Dharma University, Yogyakarta, Indonesia) for 1 week before starting the experiment. All animals were housed under standard laboratory conditions (temperature $22 \pm 3^{\circ} \mathrm{C}$ and $12 \mathrm{~h}$ light/dark cycle), fed with rodent pellet diet and water ad libitum. The study protocol was approved by Medical and Health Research Ethics Committee, Faculty of Medicine, Gadjah Mada University, Yogyakarta, Indonesia (KE/FK/0794/EC/2017).

\section{Animal grouping and treatment}

The animals were randomly divided into five groups with 5 rats in each group. Group I (normal control): animals were treated with 
Sodium CMC 1\% w/v p.o., for 6 days. Group II (toxic control): animals were treated with $\mathrm{CCl}_{4}$ in olive oil (1:1) $2 \mathrm{~mL} / \mathrm{kg}$, i.p. Groups III-V (test groups): animals were treated with 75,150 , and $300 \mathrm{mg} / \mathrm{kg}$ of MEEL p.o., for 6 days, respectively, and a single dose of $\mathrm{CCl}_{4}$ in olive oil (1:1) $2 \mathrm{~mL} / \mathrm{kg}$, i.p. was given on the seventh day. Blood samples from all groups were obtained directly through retroorbital plexus venous puncture $24 \mathrm{~h}$ after the last administration (Dongare et al., 2013; Hendra et al., 2017). The blood was allowed to coagulate and centrifuged at $3000 \mathrm{rpm}$ for $10 \mathrm{~min}$. Serum samples were used for determination of some biochemical parameters.

\section{Biochemical determinations}

All biochemical parameters were determined in a Cobas C501 analyzer using commercial kits following standard procedures.

\section{Histopathological assessment}

Rats were euthanized by cervical dislocation at the end of the experiment. Rats were dissected, livers were collected and weighted. The liver weight ratio is expressed as follows: (liver weight/body weight) x $100 \%$ (Li et al., 2017; Ekeanyanwu and Njoku, 2014). Then the organs were fixed in neutral buffered formalin. The tissues were embedded in paraffin, cut in $5 \mu \mathrm{m}$ sections and stained with hematoxylin and eosin for histopathological findings.

\section{Statistical analysis}

All the data were expressed as mean \pm SEM. Groups were compared by Kruskal-Wallis test, followed by MannWhitney test. $\mathrm{P}$ values less than 0.05 were considered. Statistical analysis was done using IBM SPSS Statistics 22.

\section{RESULTS AND DISCUSSION}

This study was designed to investigate the activity of methanolic extract of Eurycoma longifolia roots (MEEL) on some biomarker enzymes and histopathological changes of hepatic lesions indicating hepatocellular injury induced by $\mathrm{CCl}_{4}$ in rats.

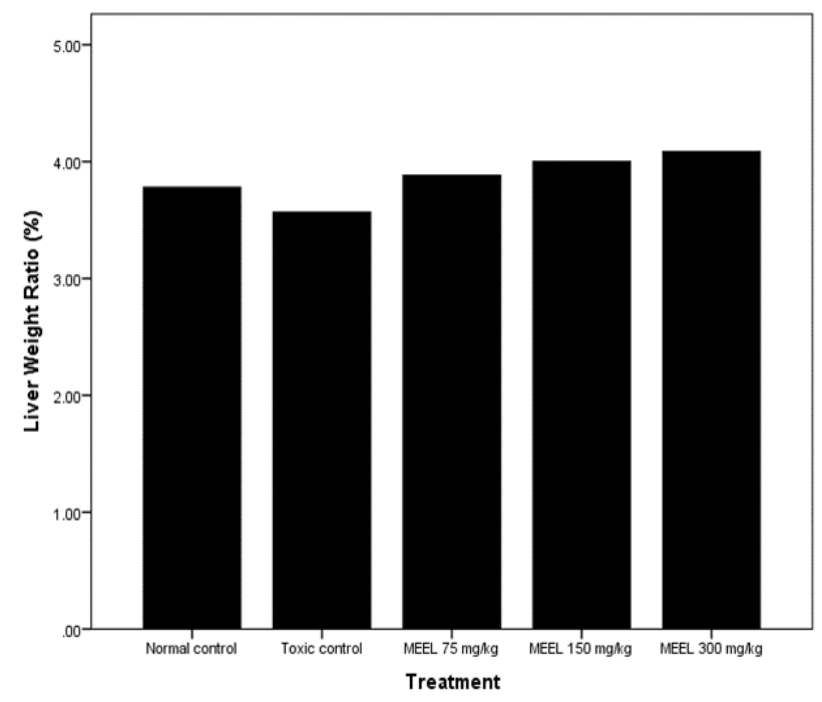

Figure 1. Effect of MEEL on liver weight ratio

Table I. Effect of MEEL on liver biochemical parameters

\begin{tabular}{lcccc}
\hline \multicolumn{1}{c}{ Treatment } & ALT $(\mathrm{U} / \mathrm{L})$ & AST $(\mathrm{U} / \mathrm{L})$ & LDH $(\mathrm{U} / \mathrm{L})$ & Albumin $(\mathrm{mg} / \mathrm{dL})$ \\
\hline Normal control & $52.8 \pm 2.5^{\mathrm{b}}$ & $140.0 \pm 7.7^{\mathrm{b}}$ & $529.0 \pm 27.1^{\mathrm{b}}$ & $3.49 \pm 0.06^{\mathrm{b}}$ \\
Toxic control & $220.5 \pm 25.0^{\mathrm{a}}$ & $839.3 \pm 16.5^{\mathrm{a}}$ & $1511.6 \pm 136.1^{\mathrm{a}}$ & $3.15 \pm 0.05^{\mathrm{a}}$ \\
MEEL 75 mg/kg & $146.9 \pm 18.6^{\mathrm{a}, \mathrm{b}}$ & $566.8 \pm 63.6^{\mathrm{a}, \mathrm{b}}$ & $851.0 \pm 31.5^{\mathrm{a}, \mathrm{b}}$ & $3.01 \pm 0.05^{\mathrm{a}}$ \\
MEEL $150 \mathrm{mg} / \mathrm{kg}$ & $134.9 \pm 11.5^{\mathrm{a}, \mathrm{b}}$ & $581.9 \pm 41.3^{\mathrm{a}, \mathrm{b}}$ & $1247.6 \pm 165.9^{\mathrm{a}}$ & $3.05 \pm 0.06^{\mathrm{a}}$ \\
MEEL 300 mg/kg & $222.2 \pm 24.8^{\mathrm{a}}$ & $743.7 \pm 38.8^{\mathrm{a}, \mathrm{b}}$ & $1158.6 \pm 102.7^{\mathrm{a}}$ & $3.12 \pm 0.08^{\mathrm{a}}$ \\
\hline
\end{tabular}

All values are expressed as mean \pm SEM, $\mathrm{n}=5$. ${ }^{\mathrm{a}} p<0.05$ when compared with normal control and ${ }^{\mathrm{b}} p<0.05$ when compared with toxic control.

Carbon tetrachloride is extensively known as an inducer for hepatotoxicity models. The elevated of serum enzyme ALT and AST as sensitive markers, are indicative of cellular leakage and loss of functional integrity of cell membranes in liver that was initiated by hepatocellular damages caused by $\mathrm{CCl}_{4}$
(Nirmala et al., 2012; Thanh et al., 2015). Changes in the activities of serum enzymes (ALT, AST and LDH) and albumin in the serum of $\mathrm{CCl}_{4}$-induced liver damage as evidence from Table I. The level of serum marker enzymes ALT, AST and LDH were found to be significantly $(\mathrm{p}<0.05)$ increased 
and albumin decreased significantly $(\mathrm{p}<0.05)$ in $\mathrm{CCl}_{4}$ treated group when compared to normal control. In the present study, significant increases in aminotransferase, $\mathrm{LDH}$ and decrease of albumin level in the $\mathrm{CCl}_{4}$ intoxicated rats represent hepatic damage, consistent with previous reports.

Treatment with MEEL $75 \mathrm{mg} / \mathrm{kg}$ significantly $(\mathrm{p}<0.05)$ prevented the elevation of ALT, AST, and LDH. MEEL $150 \mathrm{mg} / \mathrm{kg}$ reduced levels of ALT and AST significantly $(\mathrm{p}<0.05)$. Treatment with MEEL $300 \mathrm{mg} / \mathrm{kg}$ significantly $(\mathrm{p}<0.05)$ decreased levels of AST. However, there were no significant ( $>0.05$ ) increases in the level of albumin of the rats with all of the doses of MEEL.

Figure 1. shows the average liver weight ratio in the five groups animals. No significant differences in livers among all the treatments were observed.

Histopathological observation of liver tissue of the normal control group showed a normal liver architecture of hepatocytes since they were well arranged without any alteration at the central vein, while $\mathrm{CCl}_{4}$ intoxicated hepatocytes showed severe multifocal areas of fat degeneration (steatosis). Steatosis is known as a type of liver injury that may manifest as triglyceride accumulation which leads to either a micro vesicular or macro vesicular fatty liver (Sing et al., 2014). The MEEL $75 \mathrm{mg} / \mathrm{kg}$ treated group's liver sections showed less hydropic degeneration, while MEEL 150 and $300 \mathrm{mg} / \mathrm{kg}$ treated groups' liver sections showed hydropic degeneration with multifocal areas of fat degeneration.

In our study, administration of MEEL 75 $\mathrm{mg} / \mathrm{kg}$ markedly decreased the elevated aminotransaminase and $\mathrm{LDH}$ levels induced by $\mathrm{CCl}_{4} . \mathrm{A}$ dose-dependent effect was not found in the 150 and $300 \mathrm{mg} / \mathrm{kg}$ of MEEL groups when compared to the $75 \mathrm{mg} / \mathrm{kg}$ group. These trends were also found in histological observation of liver tissue. Similarly, previous study showed the hepatoprotective effect of water extract of Eurycoma longifolia at 1.5 $\mathrm{g} / \mathrm{kg}$ against $\mathrm{CCl}_{4}$-induced hepatotoxicity (Alfaqeh et al., 2010). An in vivo study reported that the methanolic extract of Eurycoma longifolia roots reduced triglyceride levels induced by glucose-fructose enriched diet and shown anti-inflammatory activity (Hendra et al., 2017). Another in vitro study confirmed that Eurycoma longifolia suppressed lipid accumulation in 3T3-L1 adipocytes (Lahrita et al., 2015). Hence, the hepatoprotective effect of methanolic extract of Eurycoma longifolia roots $75 \mathrm{mg} / \mathrm{kg}$ may be achieved by the antiinflammatory activity which may be associated with scavenging of free radicals responsible for $\mathrm{CCl}_{4}$ toxicity. Moreover, flavonoids are known as hepatoprotectives agents, so the mechanism of hepatoprotective activity of MEEL $75 \mathrm{mg} / \mathrm{kg}$ may be due to the presence of flavonoids. Preliminary phytochemical screening conducted in this study indicated MEEL contains flavonoids, tannins, phenolic compound, and terpenoids, while alkaloids were absent.

\section{CONCLUSION}

In summary, the results of this study showed that $\mathrm{CCl}_{4}$ caused hepatotoxicity and the administration of methanolic extract of Eurycoma longifolia roots $75 \mathrm{mg} / \mathrm{kg}$ to rats offered significant protection from the hepatic damage by $\mathrm{CCl}_{4}$. Evidently, histopathological examination of liver also supported the benefits of the methanolic extract of Eurycoma longifolia roots as it helped in improving liver cell architecture damage caused by $\mathrm{CCl}_{4}$. Further study should be done to characterize the hepatoprotective components of methanolic extract of Eurycoma longifolia roots.

\section{Conflict of interest statement}

We declare that we have no conflict of interest.

\section{REFERENCES}

Al-Faqeh, H.H., Muhammad, B.Y., Nafie, E.M., and Khorshid, A., 2010. The effect of Eurycoma longifolia Jack (Tongkat Ali) on Carbon Tetrachloride-Induced Liver Damage In Rats. Malay. J. Pharm. Sci., 8(2), 71-84.

Dongare, P.P., Dhande, S.R., and Kadam, V.J., 2013. Standardization of Carbon 
Tetrachloride-Induced Hepatotoxicity In the Rat. Am. J. Pharm.Tech. Res., 3(5), 438-445.

Ekeanyanwu, R.C., and Njoku, O.U., 2014. Acute and subacute oral toxicity study on the flavonoid rich fraction of Monodora tenuifolia seed in albino rats. Asian Pac. J. Trop. Biomed., 4(3), 194-202.

El-Kader, S.M.A., and Ashmawy, E.M.S.E., 2015. Non-alcoholic fatty liver disease: The diagnosis and management. World J. Hepatol., 7(6), 846-858.

Evans WC, and Trease GE., 1989. Trease and Evans Pharmacognosy. 13th ed. Bailiere Tindall: London.

Fan, J., Kim, S., and Wong, V.W., 2017. New trends on obesity and NAFLD in Asia. J. Hepatol., 7(4), 862-873.

Harborne J.B., 1973. Phytochemical Methods. Chapman and Hall: United States.

Hendra, P., Fenty, Andreani, P.R., Pangestuti, B.M.E., and Julianus, J., 2017. Evaluation of Antihyperlipidemic, Anti-Inflammatory, and Analgesic Activities of Eurycoma Longifolia in Animal Models. Int. J. Pharm. Pharm. Sci., 9(3),166-169.

Hendra, P., Jamil, O.A., Maharani, D.A., Suhadi, M.A., Putri, C.Y., Fenty., and Julianus, J., 2017. Antihyperlipidemic and Hepatoprotective Studies on Leaves of Macaranga tanarius. Asian J. Pharm. Clin. Res., 10(1), 239-241.

Jayesh, K., Helen, L.R., Vysakh, A., Binil, E., and Latha, M.S., 2017. Terminalia bellirica (Gaertn.) Roxb. fruit mitigates $\mathrm{CCl}_{4}$ induced oxidative stress and hepatotoxicity in rats. Biomed. Pharmacother., 93, 327-333.

Jothy, S.L., Zuraini, Z., and Sasidharan, S., 2011. Phytochemicals screening, DPPH free radical scavenging and xanthine oxidase inhibitiory activities of Cassia fistula seeds extract. J. Med. Plants Res., 5(10), 1941-1947.

Joshi, D., Keane, G., and Brind, A., 2015. Hepatology at a Glance. John Wiley \& Sons: United Kingdom.

Khanijo, T., and Jiraungkoorskul, W., 2016.
Review Ergogenic Effect of Long Jack, Eurycoma Longifolia. Pharmacogn. Rev., 10(20), 139-142.

Lahrita, L., Hirosawa, R., Kato, E., and Kawabata, J., 2017. Isolation and lipolytic activity of eurycomanone and its epoxy derivative from Eurycoma longifolia. Bioorganic Med. Chem., 25(17), 4829-4834.

Lahrita, L., Kato, E., and Kawabata, J., 2015. Uncovering potential of Indonesian medicinal plants on glucose uptake enhancement and lipid suppression in 3T3-L1 adipocytes. $J$. Ethnopharmacol., 168(24), 229-236.

Li, S., Tan, H., Wang, N., Zhang, Z., Lao, L., Wong, C., and Feng, Y., 2015. The Role of Oxidative Stress and Antioxidants in Liver Diseases. Int. J. Mol. Sci., 16(11), 26087-26124.

Li, L., Zhou, Y.F., Li, Y.L., Wang, L.L., Arai, $\mathrm{H}$, and $\mathrm{Xu}, \mathrm{Y} ., 2017$. In Vitro and In Vivo Antioxidative and Hepatoprotective Activity of Aqueous Extract of Cortex Dictamni. World J. Gastroenterol., 23(16), 2912-2927.

Musso, G., Gambino, R., Cassader, M., and Pagano, G., 2011. Meta-analysis: Natural History of Non-alcoholic Fatty Liver Disease (NAFLD) and Diagnostic Accuracy of Non-invasive Tests for Liver Disease Severity. Ann. Med., 43(8), 617-649.

Nirmala, M., Girija, K., Lakshman, K., and Divya, T., 2012. Hepatoprotective activity of Musa paradisiaca on experimental animal models. Asian Pac. J. Trop. Biomed., 2(1), 11-15.

Rehman, S.U., Choe, K., and Yoo, H.H., 2016. Review on a Traditional Herbal Medicine, Eurycoma longifolia Jack (Tongkat Ali): Its Traditional Uses, Chemistry, Evidence-Based Pharmacology and Toxicology. Molecules, 21(3), 1-31.

Riordan, J.D., and Nadeau, J.H., 2014. Modeling progressive non-alcoholic fatty liver disease in the laboratory mouse. Mamm. Genome, 25(9-10), 473-486. 
Singh, A., Bhat, T,K., and Sharma, O.P., 2014. Clinical Biochemistry of Hepatotoxicity. J. Clin. Toxicol., 4(1), $1-19$.

Thanh, T.B., Thanh, H.N., Minh, H.P.T., Lethi-thu, H., Ly, H.D.T., and Duc, L.V., 2015. Protective effect of Tetracera scandens $\mathrm{L}$. leaf extract against $\mathrm{CCl}_{4}$ induced acute liver injury in rats. Asian Pac. J. Trop. Biomed., 5(3), 221-227.

Varghese, C.P., Ambrose, C., Jin, S.C., Lim,
Y.J., and Keisaban, T., 2013. Antioxidant and Anti-inflammatory Activity of Eurycoma Longifolia Jack, A Traditional Medicinal Plant in Malaysia. Int. J. Pharm. Sci. Nanotechnol., 5(4), 1875-1878.

Weber, L.W.D., Boll, M., and Stampfl, A., 2003. Hepatotoxicity and Mechanism of Action of Haloalkanes: Carbon Tetrachloride as a Toxicological Model. Clin. Rev. Toxicol., 33(2), 105-136. 